\section{Use of Cardiocerebral-Protective Drug Cocktail Prior to Countershock following Prolonged Ventricular Fibrillation}

David Seaberg, MD, *James J. Menegazzi, PhD, Brian Check, BS, EMT-P, Bruce MacLeod, MD, Donald M. Yealy, MD

Mercy Hospital of Pittsburgh, Center for Emergency Medicine of Western Pennsylvania, Division of Emergency Medicine, University of Pittsburgh, Pittsburgh, Pennsylvania

Introduction: This is the third study in a series exploring the use of a "drugs-first" approach to treating prolonged ventricular fibrillation (VF). The rationale behind this approach is to prime the heart and brain prior to countershock and reperfusion.

Hypothesis: That the use of a cardiocerebral-protective cocktail would produce superior rates of return of spontaneous circulation (ROSC) and one-hour survival, when compared to a magnesium only and a concurrent control group treated with standard advanced cardiac life support (ACLS).

Methods: Twenty-four female, mixed-breed, domestic swine (mean mass $22-25 \mathrm{~kg}$ ) were used in this prospective, blinded, randomized, experimental trial. Animals were sedated (ketamine/xylazine), anesthetized (alphachloralose), paralyzed (pancuronium), mechanically ventilated on room air, and instrumented with ECG, arterial pressure, and Swan-Ganz catheters. VF was induced with a $3 \mathrm{~s}, 60 \mathrm{~Hz}, 100 \mathrm{~mA}$ transthoracic shock, and remain untreated for eight minutes. One minute of basic life support followed (standardized by use of a mechanical device). At nine minutes, animal were treated with one of three regimens: Group 1) cardiocerebral-protective cocktail (the antioxidant U-74389G $[3.0 \mathrm{mg} / \mathrm{kg}]$, epinephrine $[0.2 \mathrm{mg} / \mathrm{kg}]$, lidocaine $[1.0$ $\mathrm{mg} / \mathrm{kg}$ ], bretylium $[5.0 \mathrm{mg} / \mathrm{kg}$ ], magnesium [2.0 g], and propranolol [1.0 mg]); Group 2) magnesium [2.0 g]; and Group 3) standard ACLS. Groups 1 and 2 received drugs at minute nine (first countershock at minute 11), while Group 3 received first countershock at minute nine. Data were analyzed with two-tailed Fisher's Exact Tests, alpha $=0.05$.

Results: ROSC was achieved in Group 1, 7/7 (100\%); Group 2, 3/9, (33\%; $p$ vs. Group $1=0.01)$; and Group 3, $3 / 8(38 \% ; p$ vs. Group $1=0.02)$. One-hour survival was attained in Group 1, 7/7 (100\%); Group 2, 3/9 (33\%; $p$ vs. Group $1=0.01)$, and Group 3, $1 / 8$ (13\%; $p$ vs. Group $1=0.001$ ).

Conclusion: Cardiocerebral-protective drugs given prior to countershock produced superior rates of ROSC and one-hour survival compared to singular drug therapy (Group 2) and ACLS (Group 3).

\section{Relative Risk of Injury by Hispanic Status}

*Terence D. Valenzuela, MD, Daniel Judkins, RN, Lani L. Clark, BS, Mark Fritz, BA, David R. Hampton, PhD, Daniel W. Spaite, MD, Bruce E. Jarrell, $M D$

Department of Surgery, University of Arizona, Tucson, Arizona

Hypothesis: The relative risk of injury by mechanism differs between Hispanics and nonHispanics treated by a southwestern urban EMS system.

Methods: Design-retrospective analysis of consecutive case series transported to a level-I trauma center over 28 months in a southwestern metropolitan area, population 680,000 . Patients were identified from EMS records. A total of 4,451 patients were studied. Surname and injury mechanism were abstracted from the trauma-center registry. Hispanic status was assigned by matching surname with the 1980 census Spanish Surname List. Proportions of injured/evaluated for Hispanics vs. nonHispanics, relative risk (RR), $p$-value by Chi-square test, and the $95 \%$ confidence interval (CI) were calculated.

\section{Results:}

$\begin{array}{lcccc}\text { Mechanism } & \text { Hispanic/Non } & \text { RR } & 95 \% \text { Cl } & \text { p-value } \\ \text { Gunshot } & .10 / .04 & 1.61 & 1.30-1.99 & 0.000 \\ \text { Stabbing } & .06 / .04 & 1.53 & 1.16-2.02 & 0.003 \\ \text { Assault, blunt } & .07 / .06 & \mathbf{1 . 1 3} & 0.89-1.43 & 0.313 \\ \text { Pedestrian struck } & .07 / .06 & 1.15 & 0.91-1.46 & 0.254 \\ \text { Motor vehicle } & .51 / .51 & 0.99 & 0.93-1.06 & 0.868 \\ \text { Fall } & .06 / .08 & 0.75 & 0.59-0.96 & 0.021 \\ \text { Motorcycle } & .05 / .09 & 0.55 & 0.43-0.72 & 0.000 \\ \text { Bicycle } & .01 / .04 & 0.39 & 0.24-0.63 & 0.000\end{array}$

Conclusion: Hispanic's relative risk of penetrating trauma is high compared to the general population. Culturally relevant injury prevention interventions targeted to this at-risk population are needed. 